\title{
Un regard québécois sur la REMI
}

A Quebec Point of View about REMI

La REMI vista desde el Quebec

\section{Deirdre Meintel}

\section{CpenEdition}

\section{Journals}

Édition électronique

URL : https://journals.openedition.org/remi/8389

DOI : $10.4000 /$ remi.8389

ISSN : $1777-5418$

Éditeur

Université de Poitiers

Édition imprimée

Date de publication : 1 décembre 2016

Pagination : 335-336

ISBN : 979-10-90426-29-0

ISSN : 0765-0752

Référence électronique

Deirdre Meintel, «Un regard québécois sur la REMI », Revue européenne des migrations internationales

[En ligne], vol. 32 - n³ et 4 | 2016, mis en ligne le 01 décembre 2018, consulté le 16 avril 2022. URL http://journals.openedition.org/remi/8389 ; DOI : https://doi.org/10.4000/remi.8389 


\section{Un regard québécois sur la REMI Deirdre Meintel ${ }^{1}$}

Mon appréciation de la Revue Européenne des Migrations Internationales est inévitablement colorée par l'évolution de mes intérêts de recherche et par le fait que je travaille dans une université de langue française au Québec. "Les migrations " font partie de mes recherches depuis mes études de doctorat en anthropologie à l'Université de Brown (États-Unis), ma thèse ayant porté sur la migration des îles du Cap-Vert vers les États-Unis. Cependant, ce n'est qu'au moment où je commençais à m'intéresser aux enjeux identitaires et aux questions entourant la famille et la migration au début des années 1990 que j'ai connu la REMI. C'est dans ses pages que j'ai découvert les travaux d'auteurs tels que Michel Oriol, Marie-Antoinette Hily et Jocelyne Streiff-Fenart. Leurs recherches éclairaient mes propres travaux sur les jeunes issus de milieux immigrants, les femmes âgées immigrantes et les unions mixtes dans le contexte montréalais. Ce faisant, j'ai commencé à connaître une revue de langue française sur les questions de la migration, de l'ethnicité et du pluralisme qui était plus internationale que celles que j'avais eu l'occasion de lire jusqu'alors. Dès ses débuts, la revue s'est intéressée à l'immigration connue par d'autres pays receveurs de migrants que la France. Par ailleurs, la REMI publie depuis toujours des textes traitant des milieux d'origine des migrants qui arrivent en Europe et aux Amériques.

De ce fait, la revue a développé une personnalité qui lui est propre et que l'on pourrait qualifier de cosmopolite, accessible et contemporaine. Elle est cosmopolite en raison de son intérêt pour diverses régions du monde et divers régimes de migration et de pluralisme ; cosmopolite également en raison des provenances hétéroclites de ses auteurs, sans compter les textes publiés en anglais et en espagnol ; cosmopolite du fait de sa capacité à intégrer des articles inspirés d'approches conceptuelles développées ailleurs dans le monde. D'autre part, les numéros et les articles portant sur des phénomènes hexagonaux (les jeunes des banlieues parisiennes, par exemple) les présentent d'une façon qui les rend intelligibles pour le lecteur étranger. Ce cosmopolitisme représente un exemple pour les revues québécoises qui cherchent à être à la fois francophones, nordaméricaines et internationales.

Le style d'écriture qui caractérise la revue est exempt d'un jargon hermétique, la rendant ainsi accessible à un large public et favorisant une interdisciplinarité qui permet à des chercheurs de différentes disciplines de se pencher sur

1 Professeur d'anthropologue, Université de Montréal, Centre d'études ethniques des universités montréalaises (CEETUM), Case postale 6128, succursale Centre-ville, Montréal (QC), H3C 3J7, Canada ; deirdre.meintel@umontereal.ca 
leurs intérêts communs. En raison de cette même qualité, la REMI représente une ressource précieuse pour mes étudiants québécois généralement bilingues. Souvent, ils trouvent les textes en anglais plus conviviaux que les textes en français, en raison du style d'écriture. La revue leur offre par ailleurs des textes en français de niveau international qui sont généralement d'une agréable lisibilité.

La REMI peut être qualifiée de " contemporaine " puisqu'elle présente un visage toujours jeune après ses trois décennies d'existence. Celle-ci a évolué avec le temps en publiant des textes et des numéros portant sur des thèmes d'actualité. On pourrait signaler à titre d'exemple le numéro récent sur " Les traces de la dispersion " (vol. $30, n^{\circ} 3$ et 4,2014 ), les textes qui se trouvent dans les numéros sur "Les expériences de la santé en migration " (vol. 28, $n^{\circ} 4,2012$ ) et dans celui qui porte sur "Migration et confection " (vol. 28, $n^{\circ} 2$, 2012). Ce dernier présente des travaux empiriques sur des milieux de travail peu connus et dans lesquels se trouvent aujourd'hui bien des migrants.

Actuellement, au Québec et plus généralement au Canada, il existe deux grands problèmes relatifs à l'immigration : la déqualification et la migration temporaire. La déqualification concerne bien d'autres pays, mais elle prend une dimension systémique au Canada, puisque le pays, ainsi que la province du Québec, sélectionnent avant tout des immigrants qualifiés. Je remarque avec plaisir le travail de plusieurs collègues du CEETUM et de mon université sur cette question dans les pages de la revue. L'autre problématique, la migration temporaire, se dessine comme un enjeu majeur pour les années à venir, puisqu'elle devient de plus en plus importante au Québec et au Canada comme ailleurs dans le monde. Les conditions vécues par ces migrants temporaires ainsi que la question de leurs droits - souvent limités - préoccupent plusieurs chercheurs du CEETUM ; ces migrants représentent l'objet d'enquêtes en cours et pour les prochaines années. Évidemment, j'espère que ces chercheurs publieront les résultats de leurs recherches dans la REMI.

Permettez-moi de conclure en souhaitant au moins trois décennies de plus à la Revue Européenne des Migrations Internationales. En raison de sa pertinence sociale et scientifique, ainsi que de sa capacité à se renouveler, elle les mérite amplement. 